\title{
Exigência de proteína bruta e energia metabolizável para codornas de corte EV1
}

[Crude protein and metabolizable energy requirements for EV1 meat type quail line]

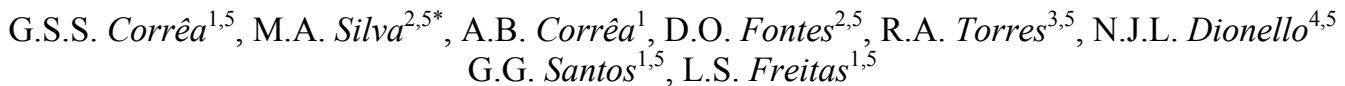 \\ ${ }^{1}$ Aluno de pós-graduação - EV-UFMG - Belo Horizonte, MG \\ ${ }^{2}$ Escola de Veterinária - UFMG \\ Caixa Postal 567 \\ 30123-970 - Belo Horizonte, MG \\ ${ }^{3}$ Departamento de Zootecnia - UFV - Viçosa, MG \\ ${ }^{4}$ Faculdade de Agronomia Eliseu Maciel - UFPel - Pelotas, RS \\ ${ }^{5}$ Bolsista do CNPq \\ RESUMO
}

\begin{abstract}
Estudou-se a exigência de proteína bruta e energia metabolizável para codornas européias EV1, durante três períodos experimentais, 7-21, 22-42 e 7-42 dias de idade, utilizando-se 576 aves, de ambos os sexos. O delineamento experimental foi inteiramente ao acaso, em arranjo fatorial 4 x 2, quatro níveis de proteína bruta $(22,24,26$ e $28 \%$ de PB) e dois níveis de energia (2900 e 3100kcal de EM/kg de ração), com seis repetições de 12 codornas por unidade experimental. O peso corporal e o ganho de peso do sétimo ao $21^{\circ}$ dia de idade foram influenciados de forma quadrática pelo nível protéico da dieta. O consumo alimentar diminuiu linearmente com o aumento do nível energético. A conversão alimentar aumentou com o aumento da PB e reduziu com o aumento do nível de EM. O peso corporal no $42^{\circ}$ dia, o ganho de peso e a conversão alimentar (7-42 dias) não foram influenciados pelos níveis de EM e PB das dietas. O nível energético $2900 \mathrm{kcal} \mathrm{de} \mathrm{EM} / \mathrm{kg}$ propiciou maior consumo em relação à dieta com $3100 \mathrm{kcal}$ de $\mathrm{EM} / \mathrm{kg}$. O máximo desempenho das codornas de corte EV1 foi alcançado com dietas formuladas com $27 \% \mathrm{~PB}$ e $2900 \mathrm{kcal}$ de EM/ $\mathrm{kg}$ no período inicial (sétimo ao $21^{\circ}$ dia de idade) e $22 \%$ de $\mathrm{PB}$ e $2900 \mathrm{kcal}$ de $\mathrm{EM} / \mathrm{kg}$ durante o período total de criação (sétimo ao $42^{\circ}$ dias de idade).
\end{abstract}

Palavras-chave: codorna de corte, proteína, energia, desempenho

\begin{abstract}
The crude protein and metabolizable energy requirement for weight gain, body weight, feed consumption, and feed consumption: weight gain ratio during three periods (7-21; 21-42 and 7-42days of age) of the growing phase of meat type quail (EV1) were estimated in a completely randomized design, with eight treatments and six replicates of 12 quails per experimental unit. The treatments consisted in a factorial combination $4 \times 2$ (22, 24, 26 e 28\% PB x 2900 e $3100 \mathrm{kcal}$ de EM/kg). Body weight and weight gain from 7 to 21 days of age were quadratic affected by protein level of diets. Feed consumption linearly decreased with the increasing of diet energetic level. Feed: weight gain ratio increased linearly with crude protein level and decreased with metabolizable energy level of diets. Body weight at 42 days of age was not affected by metabolizable energy and crude protein levels of the diets. From 7 to 42 days of age the protein and metabolizable energy of diets did not affect quail body weight and feed: weight gain ratio. Quails fed on 2900kcal of EM/kg of diet showed higher feed consumption in comparison to quails fed on $3100 \mathrm{kcal}$ of EM/kg diets. Maximum performance of EV1 quails are reached in diets with $27 \%$ of crude protein $(C P)$ and $2900 \mathrm{kcal}$ of $\mathrm{ME} / \mathrm{kg}$ of diet in the initial period (7-21 days of age) and 22\% of CP and 2900kcal of ME/kg of diet in the whole period (7-42 days of age).
\end{abstract}

Keywords: meat type quail, protein, energy, performance

Recebido em 30 de agosto de 2006

Aceito em 18 de maio de 2007

*Autor para correspondência (corresponding author)

E-mail: martinho@vet.ufmg.br

Apoio: $\mathrm{CNPq}$ 


\section{INTRODUÇÃO}

As codornas de corte apresentam maiores pesos e taxas de crescimento que as de postura (Corrêa et al., 2006). Entretanto, há pouca informação sobre a nutrição de codornas européias para a fase de crescimento e, ao analisar as tabelas disponíveis (Nutrient..., 1994), observa-se que há grande variação dos níveis nutricionais recomendados para as diferentes fases.

Como a alimentação representa a maior parte dos custos variáveis de uma atividade avícola e os teores de proteína bruta e energia metabolizável influem decisivamente no desempenho de codornas, é de extrema importância a estimativa de suas exigências para que se formulem dietas de mínimo custo ou de máximo retorno (Oliveira et al., 2002b). O comprometimento do desempenho produtivo das codornas pode ser evidenciado no desempenho das aves que consomem dietas cujos valores de energia metabolizável são diferentes de suas exigências energéticas (Oliveira et al., 2007).

Ao estudarem o efeito de dietas com 20, 25, 30 e $35 \%$ de proteína bruta para codornas japonesas em crescimento, Vohra e Roudybush (1971) sugeriram dietas com $25 \%$ de PB e $2880 \mathrm{kcal}$ de EM/kg de dieta. Rajini e Narahari (1998) avaliaram o desempenho de codornas em crescimento alimentadas com dietas contendo níveis de 24 a $28 \%$ de proteína bruta (PB) de um a 21 dias de idade e níveis de 18 a $22 \%$ de PB de 22 a 42 dias de idade e níveis de 2400 a $2800 \mathrm{kcal}$ de $E M / k g$ de dieta em ambos os períodos e verificaram maior ganho de peso e melhor conversão alimentar do primeiro ao $21^{\circ}$ dia de idade com dietas contendo $28 \%$ PB, independente do nível energético. Do $22^{\circ}$ ao $42^{\circ}$ de idade, os autores observaram que dietas com $20 \%$ PB promoveram melhores ganho de peso e conversão alimentar independente do nível energético. Oliveira et al. (2000) sugeriram níveis de 24 ou $26 \%$ de $\mathrm{PB}$ para alimentação de machos de codornas japonesas, não especializadas para corte, até o $28^{\circ}$ dia e nível de 18 a $20 \%$ de $\mathrm{PB}$ do $29^{\circ}$ ao $45^{\circ}$ dia de idade.

Dietas com relações calórico-protéicas mais amplas (menos protéicas) promovem maior consumo de energia ou ingestão deficiente de proteína. Por outro lado, em dietas com relações mais estreitas (mais protéicas), o consumo de energia é menor, e as carcaças são mais magras (Summers et al., 1988, Bartov, 1998).

Apesar de o nível energético ser o principal determinante do consumo, quando o conteúdo protéico da dieta é menor do que a exigência, as aves tendem a aumentar o consumo, para compensar principalmente o menor conteúdo de aminoácidos (Chwalibog e Baldwin, 1995).

Murakami et al. (1993), ao estudarem os níveis nutricionais protéicos e energéticos, por meio de dietas formuladas à base de milho e farelo de soja, com 2800 e $3000 \mathrm{kcal}$ de EM/kg e 20 a $26 \%$ de PB para codornas japonesas em crescimento, verificaram que, atendidas as exigências de metionina + cistina, o menor consumo total de dieta, peso médio no $42^{\circ}$ dia de idade e conversão alimentar do primeiro ao $42^{\circ}$ dia de idade foram observados com codornas alimentadas com $20 \%$ de PB e $3000 \mathrm{kcal}$ de $\mathrm{EM} / \mathrm{kg}$.

Assim, o objetivo deste trabalho foi estimar as exigências de proteína bruta e energia metabolizável para o máximo desempenho de codornas de corte.

\section{MATERIAL E MÉTODOS}

Utilizaram-se 576 codornas de corte EV1, de ambos os sexos, do sétimo ao $42^{\circ}$ dia de idade, com peso médio inicial de 24,0g. O delineamento experimental foi inteiramente ao acaso, em arranjo fatorial 4 x 2 (níveis de PB x EM), com seis repetições de 12 codornas por unidade experimental.

As dietas experimentais (Tab. 1) resultantes das combinações dos níveis de proteína bruta $(22$, 24, 26 e $28 \%$ ) e energia metabolizável (2900 e $3100 \mathrm{kcal}$ de $\mathrm{EM} / \mathrm{kg}$ de dieta) foram formuladas com base nas composições dos ingredientes apresentadas por Rostagno et al. (2000) e as exigências nutricionais das codornas, de acordo com o NRC (Nutrient..., 1994), exceto para os níveis de $\mathrm{PB}$ e EM.

O programa de luz utilizado foi contínuo (24 horas de luz natural + artificial) durante todo o período experimental. 
Tabela 1. Composição das dietas experimentais utilizadas para codornas de corte do $7^{\circ}$ ao $42^{\circ}$ dia de idade, de acordo com os tratamentos

\begin{tabular}{|c|c|c|c|c|c|c|c|c|}
\hline \multirow[t]{2}{*}{ Ingrediente (\%) } & \multicolumn{4}{|c|}{$\begin{array}{c}2900 \mathrm{kcal} \mathrm{EM} / \mathrm{kg} \\
\text { Proteína bruta (\%) }\end{array}$} & \multicolumn{3}{|c|}{$\begin{array}{l}3100 \mathrm{kcal} \mathrm{EM} / \mathrm{kg} \\
\text { Proteína bruta }(\%)\end{array}$} & \multirow[b]{2}{*}{28} \\
\hline & 22 & 24 & 26 & 28 & 22 & 24 & 26 & \\
\hline Milho & 53,60 & 47,08 & 40,56 & 34,03 & 53,44 & 46,91 & 40,39 & 33,87 \\
\hline Farelo de soja & 36,54 & 42,05 & 47,56 & 53,07 & 37,64 & 43,15 & 48,66 & 54,17 \\
\hline Farelo de trigo & 4,00 & 4,00 & 4,00 & 4,00 & 1,00 & 1,00 & 1,00 & 1,00 \\
\hline Óleo de soja & 2,60 & 3,66 & 4,73 & 5,80 & 4,64 & 5,71 & 6,78 & 7,84 \\
\hline Calcário & 1,11 & 1,08 & 1,06 & 1,04 & 1,09 & 1,06 & 1,04 & 1,02 \\
\hline Fosfato bicálcico & 0,95 & 0,92 & 0,90 & 0,86 & 0,99 & 0,96 & 0,93 & 0,90 \\
\hline Suplem. min. e vit. ${ }^{1}$ & 0,50 & 0,50 & 0,50 & 0,50 & 0,50 & 0,50 & 0,50 & 0,50 \\
\hline Sal comum & 0,27 & 0,27 & 0,26 & 0,25 & 0,27 & 0,27 & 0,26 & 0,26 \\
\hline DL- metionina & 0,09 & 0,14 & 0,18 & 0,23 & 0,10 & 0,15 & 0,19 & 0,24 \\
\hline L-treonina & 0,07 & 0,10 & 0,13 & 0,16 & 0,07 & 0,11 & 0,14 & 0,17 \\
\hline Inerte & 0,27 & 0,20 & 0,12 & 0,05 & 0,26 & 0,18 & 0,11 & 0,03 \\
\hline Total & 100,00 & 100,00 & 100,00 & 100,00 & 100,00 & 100,00 & 100,00 & 100,00 \\
\hline \multicolumn{9}{|l|}{ Composição calculada } \\
\hline Proteína bruta (\%) & 22,00 & 24,00 & 26,00 & 28,00 & 22,00 & 24,00 & 26,00 & 28,00 \\
\hline En. metab. (kcal/kg) & 2900 & 2900 & 2900 & 2900 & 3100 & 3100 & 3100 & 3100 \\
\hline Cálcio (\%) & 0,80 & 0,80 & 0,80 & 0,80 & 0,80 & 0,80 & 0,80 & 0,80 \\
\hline Fósf. disponível (\%) & 0,30 & 0,30 & 0,30 & 0,30 & 0,30 & 0,30 & 0,30 & 0,30 \\
\hline Met.+Cist. (\%) & 0,78 & 0,87 & 0,96 & 1,05 & 0,78 & 0,87 & 0,96 & 1,05 \\
\hline Metionina (\%) & 0,53 & 0,60 & 0,67 & 0,74 & 0,54 & 0,61 & 0,68 & 0,75 \\
\hline Lisina $(\%)$ & 1,17 & 1,31 & 1,45 & 1,59 & 1,19 & 1,32 & 1,46 & 1,60 \\
\hline Treonina $(\%)$ & 0,92 & 1,02 & 1,13 & 1,24 & 0,92 & 1,03 & 1,14 & 1,25 \\
\hline
\end{tabular}

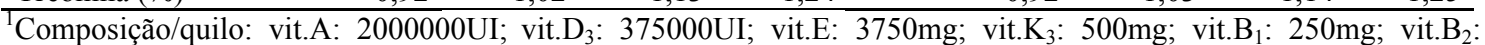
750mg; vit. $\mathrm{B}_{6}: 500 \mathrm{mg}$; vit. $\mathrm{B}_{12}$ : $3750 \mathrm{mcg}$; niacina: $6250 \mathrm{mg}$; ac. pantotênico: $2500 \mathrm{mg}$; biotina: $10 \mathrm{mg}$; ac. fólico: 125mg; colina: $75000 \mathrm{mg}$; metionina: $250000 \mathrm{mg}$; selênio: $45 \mathrm{mg}$; iodo: $175 \mathrm{mg}$; ferro: $12525 \mathrm{mg}$; cobre: $2500 \mathrm{mg}$; manganês: 19500mg; zinco: 13750mg; avilamicina: 15000mg; narasin: $12250 \mathrm{mg}$; B.H.T.: 500mg; vit.C: $12500 \mathrm{mg}$.

As variáveis estudadas foram o peso ao final de cada fase (g/ave), o ganho de peso (g/ave), o consumo de ração (g/ave) e a conversão alimentar (g de dieta/g ganho de peso) durante os períodos inicial (sete a 21 dias), final (22 a 42 dias) e período total (sete a 42 dias).

As análises dos dados foram realizadas por meio do programa SAEG (Sistema..., 2004). Os efeitos dos níveis de proteína bruta foram calculados por análise de regressão, ao desdobrar os graus de liberdade dos fatores em seus componentes lineares e quadráticos para escolha do modelo de regressão que melhor descrevesse as observações.

\section{RESULTADOS E DISCUSSÃO}

Não houve interações significativas entre os níveis de proteína bruta e energia metabolizável para as variáveis estudadas do sétimo ao $21^{\circ}$ dia de idade (Tab. 2).
$\mathrm{O}$ peso médio no $21^{\circ}$ dia e o ganho do peso do sétimo ao $21^{\circ}$ dia (Tab. 2) foram influenciados apenas pelo nível protéico da dieta $(\mathrm{P}<0,05)$. Observou-se efeito quadrático dos níveis de proteína bruta da dieta sobre essas variáveis, segundo as equações $\hat{Y}_{i}=-243,68+27,62 \mathrm{X}_{\mathrm{i}}$ $0,51 \mathrm{X}_{i}^{2}$ e $\hat{Y}_{i}=280,29+28,61 \mathrm{X}_{\mathrm{i}}-0,53 \mathrm{X}_{i}^{2}$, respectivamente. $\mathrm{O}$ peso e o ganho de peso aumentaram até o nível de 27,1 e $27,0 \%$ de proteína bruta, respectivamente, diminuindo a partir desse nível.

Os resultados indicaram que o peso e o ganho de peso durante a fase de crescimento foram altamente dependentes da ingestão diária de proteína para suprir suas necessidades fisiológicas e potencializar a deposição protéica, o que é desejável, pois o baixo peso corporal pode prejudicar a comercialização, por não atender às exigências do mercado. 


\section{Corrêa et al.}

Tabela 2. Peso médio das codornas $(\mathrm{g})$, ganho de peso médio $(\mathrm{g})$, consumo de dieta ( $\mathrm{g}$ ) e conversão alimentar $(\mathrm{g} / \mathrm{g})$ em função dos níveis de proteína bruta e energia metabolizável das dietas durante a fase inicial de sete a 21 dias de idade

\begin{tabular}{|c|c|c|c|c|c|}
\hline Variável & & $\begin{array}{l}\text { Peso corporal } \\
\text { (g/ave) }\end{array}$ & $\begin{array}{l}\text { Ganho de peso } \\
\text { (g/ave) }\end{array}$ & $\begin{array}{l}\text { Consumo de dieta } \\
(\mathrm{g})\end{array}$ & $\begin{array}{c}\text { Conversão } \\
\text { alimentar }(\mathrm{g} / \mathrm{g})\end{array}$ \\
\hline \multirow{5}{*}{$\begin{array}{l}\text { Proteína bruta } \\
\qquad(\%)\end{array}$} & 22 & 117,06 & 93,04 & 213,52 & 2,31 \\
\hline & 24 & 124,86 & 101,46 & 213,55 & 2,10 \\
\hline & 26 & 129,79 & 105,92 & 217,33 & 2,05 \\
\hline & 28 & 129,42 & 105,87 & 211,62 & 2,00 \\
\hline & Média & 125,29 & 101,53 & 214,00 & 2,12 \\
\hline \multirow{3}{*}{$\begin{array}{c}\text { Energia metabolizável } \\
(\mathrm{kcal} / \mathrm{kg})\end{array}$} & 2900 & $124,81 \mathrm{a}$ & $107,07 a$ & $218,08 \mathrm{a}$ & $2,17 b$ \\
\hline & 3100 & $125,77 \mathrm{a}$ & $102,07 \mathrm{a}$ & $209,92 b$ & $2,06 \mathrm{a}$ \\
\hline & Média & 125,29 & 101,53 & 214,00 & 2,12 \\
\hline $\mathrm{CV}$ & & 4,57 & 5,29 & 5,24 & 6,27 \\
\hline $\begin{array}{l}\text { Nível de significância do } \\
\text { efeito da proteína }\end{array}$ & & $\mathrm{P}<0,01 * *$ & $\mathrm{P}<0,01 * *$ & n.s & $\mathrm{P}<0,01^{*}$ \\
\hline $\begin{array}{l}\text { Nível de significância do } \\
\text { efeito da energia }\end{array}$ & & n.s & n.s & $\mathrm{P}<0,01$ & $\mathrm{P}<0,01$ \\
\hline \multirow[t]{2}{*}{$\begin{array}{l}\text { Nível de significância do } \\
\text { efeito da prot. } x \text { energia }\end{array}$} & & n.s & n.s & n.s & n.s \\
\hline & \multicolumn{3}{|c|}{$\begin{array}{c}\text { Equações de regressão das variáveis respostas } \\
\text { em relação ao nível de proteína da dieta }\end{array}$} & $\mathrm{R}^{2}$ & $\begin{array}{c}\text { Ponto de máximo } \\
\text { desempenho }\end{array}$ \\
\hline Peso corporal (g) & \multicolumn{3}{|c|}{$\hat{Y}_{i}=-243,68+27,62 \mathrm{X}_{\mathrm{i}}-0,51 \mathrm{X}_{i}^{2}$} & 1,00 & 27,08 \\
\hline Ganho de peso (g) & \multicolumn{3}{|c|}{$\hat{Y}_{i}=280,29+28,61 \mathrm{X}_{\mathrm{i}}-0,53 \mathrm{X}_{i}^{2}$} & 1,00 & 27,00 \\
\hline $\begin{array}{l}\text { Conversão alimentar } \\
(\mathrm{g} / \mathrm{g})\end{array}$ & \multicolumn{3}{|c|}{$\hat{Y}_{i}=3,33-0,048 \mathrm{X}_{\mathrm{i}}$} & 0,99 & 28,00 \\
\hline
\end{tabular}

Médias seguidas por letras distintas, na coluna, diferem entre si pelo teste Fisher $(\mathrm{P}<0,05)$.

*Efeito linear, ${ }^{* *}$ efeito quadrático, ${ }^{\text {ns }}$ não significativo

Resultados semelhantes foram observados por Lee et al. (1977), ao trabalharem com exigências protéicas de codornas japonesas em crescimento, indicaram nível inicial de 28 a $32 \%$ de PB para melhor crescimento. Hyánková et al. (1997) observaram melhor desempenho em codornas japonesas alimentadas com dietas contendo $26 \%$ de PB durante a fase inicial.

Rajini e Narahari (1998) verificaram melhor ganho de peso em codornas japonesas alimentadas no período do nascimento às três semanas com dietas contendo $28 \%$ de $\mathrm{PB}$, independente do nível energético e de quatro a seis semanas os níveis recomendados seria $20 \%$ de PB para promover o melhor ganho de peso.

Corrêa et al. (2007) observaram maior ganho de peso de codornas de corte alimentadas com 28 e $25,71 \%$ de proteína bruta e $3100 \mathrm{kcal}$ de $\mathrm{EM} / \mathrm{kg}$ durante o período de sete-14 dias e de 15-21 dias de idade, respectivamente.

Oliveira et al. (2002b), trabalhando com dietas contendo 18 a $26 \%$ de proteína bruta para codornas japonesas visando à produção de carne, observaram efeito linear crescente dos níveis protéicos sobre o ganho de peso no período de cinco a 27 dias de idade.

O consumo alimentar durante a fase inicial de crescimento diminuiu com o aumento do nível energético da dieta (Tab. 2). Estes resultados são similares aos descritos por Corrêa et al. (2007) e Freitas et al. (2004) que observaram maior consumo em codornas de corte alimentadas com dietas de 3100 e $3150 \mathrm{kcal}$ de EM/kg, respectivamente.

Murakami et al. (1993), ao estudarem os níveis de 2800 e $3000 \mathrm{kcal}$ de EM/kg em dietas com 20, 22, 24 e 26\% PB para codornas japonesas, verificaram que os níveis protéicos e energéticos para o máximo desempenho foram de $20 \%$ de PB e $3000 \mathrm{kcal}$ de EM/ kg de dieta. Entretanto, Begin (1968) não verificou diferença no desempenho de codornas na segunda semana de idade quando alimentadas com dois níveis energéticos (3380 e $2180 \mathrm{kcal}$ de $\mathrm{EM} / \mathrm{kg}$ ) de dieta. Oliveira et al. (2002b) observaram que no nível de 18\% de 
proteína bruta na dieta houve efeito quadrático dos níveis de energia sobre o consumo alimentar, com menor consumo nos níveis de $3022,73 \mathrm{kcal}$ de EM/kg e efeito linear negativo de energia metabolizável sobre o consumo nos níveis de 20 , 22,24 e $26 \%$ de PB, ou seja, maior consumo foi observado nas codornas alimentadas com dietas contendo $2800 \mathrm{kcal}$ de $\mathrm{EM} / \mathrm{kg}$.

O aumento da EM das dietas reduziu a ingestão de proteína das codornas por diminuir o consumo da dieta. Oliveira et al. (2002a) observaram efeitos quadráticos do nível de EM sobre o consumo da dieta, com mínimos estimados de consumo para 3168 e $3023 \mathrm{kcal}$ de $\mathrm{EM} / \mathrm{kg}$, em dietas contendo 26 e $18 \%$ de proteína bruta, respectivamente.

Os níveis de PB e EM das dietas nesta fase influenciaram a conversão alimentar (Tab. 2) que melhorou linearmente com o aumento do nível de $\mathrm{PB}$ da dieta, segundo equação $\hat{Y}_{i}=3,33-$ $0,048 \mathrm{X}_{\mathrm{i}}$.

Melhor conversão alimentar foi observada nas codornas alimentadas com dietas contendo $3100 \mathrm{kcal}$ de EM/kg. Como a conversão alimentar é uma relação direta entre o consumo de ração e o ganho de peso, o efeito não significativo do nível da energia sobre o ganho de peso é resultado do fato de as codornas regularem o consumo de ração em função do nível de energia da dieta, o que resulta em menor consumo com o aumento da EM da dieta e, conseqüentemente, influencia diretamente a conversão alimentar. Resultados semelhantes foram observados por Oliveira et al. (2003), os quais verificaram que dietas contendo nível de $3000 \mathrm{kcal}$ de EM/kg apresentaram melhor conversão alimentar, sendo $25,8 \%$ menor que dietas contendo $2900 \mathrm{kcal}$ de $\mathrm{EM} / \mathrm{kg}$.

Oliveira et al. (2002a) não observaram efeito dos níveis protéicos estudados (18 a 26\%) sobre a conversão alimentar de codornas japonesas do quinto ao $27^{\circ}$ dia de idade.

Não houve efeito significativo dos níveis de energia metabolizável e proteína bruta das dietas sobre o peso das codornas no $42^{\circ}$ dia de idade
(Tab. 3). Isso indica uma menor exigência de energia e proteína nesta fase. Resultados semelhantes foram observados por Corrêa et al. (2005) que, ao avaliarem dietas contendo 22 a $28 \%$ de proteína bruta e 2900a 3100kcal de $\mathrm{EM} / \mathrm{kg}$, não observaram efeitos significativos sobre o peso aos 42 dias de idade e por Murakami et al (1993), os quais também não verificaram diferença no peso das codornas japonesas no $42^{\circ}$ dia com dietas contendo 2800 e $3000 \mathrm{kcal} / \mathrm{kg}$, e Farrel et al. (1982), que relataram ingestão decrescente de energia até três semanas de idade em codornas, permanecendo constante após este período.

Corrêa et al. (2007) observaram máximo peso corporal no $42^{\circ}$ dia de idade, em codornas de corte, quando alimentadas com dietas contendo $28,0 \%$ de proteína bruta e $2900 \mathrm{kcal}$ de EM/kg de alimento.

O ganho de peso decresceu linearmente com o aumento do nível protéico das dietas, durante o período de 22-42 dias de idade, segundo a equação $\hat{\mathrm{Y}}_{\mathrm{i}}=181,33-1,841 \mathrm{X}_{\mathrm{i}}$, o que pode ser explicado pela redução linear significativa do consumo alimentar, segundo equação $\hat{\mathrm{Y}}_{\mathrm{i}}=$ $725,83-2,903 \mathrm{X}_{\mathrm{i}}$, em função do nível protéico (Tab. 3). Oliveira et al. (2000) encontraram melhores ganhos de peso, em codornas japonesas machos, do $28^{\circ}$ ao $45^{\circ}$ dia de idade, com os níveis de 18 e 20\% de PB. Lepore e Marks (1971) e Marks (1993) obtiveram melhores pesos na quarta e sexta semanas em codornas de corte de ambos os sexos, com níveis de proteína bruta entre 24 e $27 \%$, embora não tenham observado efeito significativo sobre o ganho de peso das codornas.

Nessa fase (22-42 dias de idade), as codornas alimentadas com dietas com menor nível energético apresentaram maior consumo de dieta. Estes resultados também dão sustentação à teoria quimiostática de controle de ingestão de alimento, em que as aves alimentadas com dietas com menores valores energéticos consomem mais alimento. 


\section{Corrêa et al.}

Tabela 3. Peso médio das codornas (g), ganho de peso médio (g), consumo de dieta (g) e conversão alimentar $(\mathrm{g} / \mathrm{g})$ em função dos níveis de proteína bruta e energia metabolizável das dietas durante a fase de 22 a 42 dias de idade

\begin{tabular}{|c|c|c|c|c|c|}
\hline Variável & & $\begin{array}{l}\text { Peso corporal } \\
\text { (g/ave) }\end{array}$ & $\begin{array}{l}\text { Ganho de peso } \\
\text { (g/ave) }\end{array}$ & $\begin{array}{l}\text { Consumo de } \\
\operatorname{dieta}(\mathrm{g})\end{array}$ & $\begin{array}{c}\text { Conversão } \\
\text { alimentar }(\mathrm{g} / \mathrm{g})\end{array}$ \\
\hline \multirow{5}{*}{$\begin{array}{l}\text { Proteína bruta } \\
\qquad(\%)\end{array}$} & 22 & 257,22 & 140,90 & 682,24 & 4,85 \\
\hline & 24 & 263,29 & 138,18 & 696,00 & 5,05 \\
\hline & 26 & 261,08 & 131,10 & 671,82 & 5,13 \\
\hline & 28 & 260,41 & 130,99 & 670,94 & 5,14 \\
\hline & Média & 260,50 & 135,29 & 680,25 & 5,04 \\
\hline \multirow{3}{*}{$\begin{array}{c}\text { Energia metabolizável } \\
(\mathrm{kcal} / \mathrm{kg})\end{array}$} & 2900 & $261,65 a$ & $136,62 \mathrm{a}$ & $690,99 a$ & $5,07 \mathrm{a}$ \\
\hline & 3100 & $259,35 \mathrm{a}$ & $133,96 a$ & $669,50 \mathrm{~b}$ & $5,01 \mathrm{a}$ \\
\hline & Média & 260,50 & 135,29 & 680,25 & 5,04 \\
\hline $\mathrm{CV}$ & & 3,37 & 4,80 & 3,09 & 6,23 \\
\hline $\begin{array}{l}\text { Nível de significância do } \\
\text { efeito da proteína }\end{array}$ & & n.s & $\mathrm{P}<0,01^{*}$ & $\mathrm{P}<0,01^{*}$ & $\mathrm{P}<0,01^{*}$ \\
\hline $\begin{array}{l}\text { Nível de significância do } \\
\text { efeito da energia }\end{array}$ & & n.s & n.s & $\mathrm{P}<0,01$ & n.s \\
\hline \multirow[t]{2}{*}{$\begin{array}{l}\text { Nível de significância do } \\
\text { efeito da prot } \mathrm{x} \text { energia }\end{array}$} & & n.s & n.s & n.s & n.s \\
\hline & \multicolumn{3}{|c|}{$\begin{array}{l}\text { Equações de regressão das variáveis } \\
\text { respostas em relação ao nível de } \\
\text { proteína da dieta }\end{array}$} & $\mathrm{R}^{2}$ & $\begin{array}{l}\text { Ponto de máximo } \\
\text { desempenho }\end{array}$ \\
\hline Ganho de Peso (g) & \multicolumn{3}{|c|}{$\hat{Y}_{i}=181,33-1,841 \mathrm{X}_{\mathrm{i}}$} & 0,89 & 22,00 \\
\hline Ganho de peso (g) & \multicolumn{3}{|c|}{$\hat{Y}_{i}=280,29-2,903 \mathrm{X}_{\mathrm{i}}$} & 0,41 & 22,00 \\
\hline Conversão alimentar (g/g) & \multicolumn{3}{|c|}{$\hat{Y}_{i}=3,84-0,048 \mathrm{X}_{\mathrm{i}}$} & 0,83 & 22,00 \\
\hline
\end{tabular}

Médias seguidas por letras distintas, na coluna, diferem entre si pelo teste Fisher $(\mathrm{P}<0,05)$.

${ }^{*}$ Efeito linear, ${ }^{\mathrm{ns}}$ não significativo

Chwalibog e Baldwin (1995) relataram que, apesar do nível de energia ser o principal fator determinante do consumo, as aves também aumentam o consumo alimentar para compensar o menor conteúdo em aminoácidos das dietas com menor conteúdo protéico.

Fridrich et al. (2005), estudando níveis de proteína bruta para codornas de corte que variaram de 18 a $26 \%$, não verificaram efeito da proteína no peso corporal nos períodos de 18 a 28 e 28 a 45 dias de idade e no ganho de peso no período de 18 a 28 dias de idade.

A conversão alimentar piorou linearmente em função do aumento do nível protéico da dieta, segundo a equação $\hat{Y}_{i}=3,84+0,048 \mathrm{X}_{\mathrm{i}}$. Isso era esperado, pois a conversão é relação direta entre o consumo de alimento e o ganho de peso que decresceu linearmente em função do nível protéico da dieta. A conversão não foi influenciada pelos níveis de energia da dieta.
Fridrich et al. (2005) não observaram efeito dos níveis protéicos estudados (18 a $26 \%$ ) sobre a conversão alimentar de codornas de corte no período de 18-28 dias de idade.

Não houve efeito significativo dos níveis de proteína bruta e energia metabolizável sobre o ganho de peso e conversão alimentar no período total de criação (sétimo ao $42^{\circ} \mathrm{dia}$ ), conforme observado na Tab. 4.

O nível energético da dieta influiu no consumo alimentar, de tal forma que codornas alimentadas com dietas com o nível energético mais baixo (2900) apresentaram maior consumo alimentar.

Resultados semelhantes foram obtidos por Murakami et al. (1993) que observaram maior consumo de dieta em codornas japonesas alimentadas com dietas contendo $2800 \mathrm{kcal}$ de $\mathrm{EM} / \mathrm{kg}$, em comparação às alimentadas com dietas contendo $3000 \mathrm{kcal}$ de $\mathrm{EM} / \mathrm{kg}$ de dieta do primeiro ao $42^{\circ}$ dia de idade. 
Tabela 4. Peso médio das codornas $(\mathrm{g})$, ganho de peso médio $(\mathrm{g})$, consumo de dieta $(\mathrm{g})$ e conversão alimentar $(\mathrm{g} / \mathrm{g})$ em função dos níveis de proteína bruta e energia metabolizável das dietas durante a fase de sete a 42 dias de idade

\begin{tabular}{|c|c|c|c|c|}
\hline Variável & & $\begin{array}{l}\text { Ganho de peso } \\
\text { (g/ave) }\end{array}$ & $\begin{array}{l}\text { Consumo de dieta } \\
\text { (g) }\end{array}$ & $\begin{array}{c}\text { Conversão } \\
\text { alimentar }(\mathrm{g} / \mathrm{g})\end{array}$ \\
\hline \multirow{5}{*}{$\begin{array}{l}\text { Proteína bruta } \\
\qquad(\%)\end{array}$} & 22 & 233,94 & 895,75 & 3,84 \\
\hline & 24 & 239,64 & 909,54 & 3,80 \\
\hline & 26 & 237,02 & 889,15 & 3,75 \\
\hline & 28 & 236,86 & 882,56 & 3,73 \\
\hline & Média & 236,86 & 894,25 & 3,78 \\
\hline \multirow{3}{*}{$\begin{array}{c}\text { Energia metabolizável } \\
(\mathrm{kcal} / \mathrm{kg})\end{array}$} & 2900 & $237,69 \mathrm{a}$ & $909,07 \mathrm{a}$ & $3,83 \mathrm{a}$ \\
\hline & 3100 & $236,04 \mathrm{a}$ & $879,44 \mathrm{~b}$ & $3,73 \mathrm{a}$ \\
\hline & Média & 236,86 & 894,25 & 5,04 \\
\hline $\mathrm{CV}$ & & 3,72 & 2,71 & 4,57 \\
\hline $\begin{array}{l}\text { Nível de significância do } \\
\text { efeito da proteína }\end{array}$ & & n.s & n.s & n.s \\
\hline $\begin{array}{c}\text { Nível de significância do } \\
\text { efeito da energia }\end{array}$ & & n.s & $\mathrm{P}<0,01$ & n.s \\
\hline $\begin{array}{l}\text { Nível de significância do } \\
\text { efeito da prot } \mathrm{x} \text { energia }\end{array}$ & & n.s & n.s & n.s \\
\hline
\end{tabular}

Médias seguidas por letras distintas, na coluna, diferem entre si pelo teste Fisher $(\mathrm{P}<0,05)$.

${ }^{\text {ns }}$ não significativo

\section{CONCLUSÕES}

As exigências em proteína bruta e energia metabolizável para maior ganho de peso das codornas de corte EV1 são $27 \%$ PB e $2900 \mathrm{kcal}$ de $\mathrm{EM} / \mathrm{kg}$ para o período inicial (sétimo ao $21^{\circ}$ dia de idade) e bom desempenho foi observado com dietas contendo $22 \%$ de PB e $2900 \mathrm{kcal}$ de $\mathrm{EM} / \mathrm{kg}$ para o período final $\left(22^{\circ}\right.$ ao $42^{\circ}$ dia de idade) e $22 \%$ de $\mathrm{PB}$ e $2900 \mathrm{kcal}$ de $\mathrm{EM} / \mathrm{kg}$ para o período total de criação (sétimo ao $42^{\circ}$ dia de idade).

\section{REFERÊNCIAS BIBLIOGRÁFICAS}

BARTOV, I. Lack of interrelationship between the effets of dietary factors and food withdrawal on carcass quality of broils chickens. Br. Poult. Sci., v.39, p.426-433, 1998.

BEGIN, J.J. A comparison of the ability of the japonese quail and light breed chicken to metabolize and utilize energy. Poult. Sci., v.47, p.1278-1281, 1968.

CORRÊA, G.S.S.; SILVA, M.A.; FONTES, D.O. et al. Efeito de diferentes níveis de proteína e energia sobre o rendimento de carcaça de codornas européias. Arq. Bras. Med. Vet. Zootec., v.57, p.266-271, 2005.
CORRÊA, G.S.S.; SILVA, M.A.; CORRÊA, A.B. et al. Exigência de metionina + cistina total para codornas de corte em crescimento. Arq. Bras. Med. Vet. Zootec., v.58, p.414-420, 2006.

CORRÊA, G.S.S.; SILVA, M.A.; CORRÊA, A.B. et al. Exigências de proteína bruta e energia metabolizável em codornas de corte durante a fase de crescimento. Arq. Bras. Med. Vet. Zootec., v.59, p.488-494, 2007.

CHWALIBOG, A.; BALDWIN, R. L. Sistems to predict the energy and requirements of laying fowl. World's Poult. Sci., v.51, p.188-195, 1995.

FARREL, D.J.; ATMAMIHARDJA, S.I.; PYM, R.A.E. Calorimetric measurements of the energy and nitrogen metabolism of japanese quail. $\mathrm{Br}$. Poult. Sci., v.23, p.375-382, 1982.

FREITAS, A.C.; FUENTES, M.F.F.; FREITAS, E. R. et al. Efeito de diferentes níveis de proteína bruta e de energia metabolizável sobre o desempenho de codornas de postura. In: REUNIÃO ANUAL DA SOCIEDADE BRASILEIRA DE ZOOTECNIA, 14., 2004, Campo Grande. Anais... Campo Grande: SBZ, 2004.

FRIDRICH, A.B.; VALENTE, B.D.; FELIPESILVA, A.S. et al. Exigência de proteína bruta para codornas européias no período de crescimento. Arq. Bras. Med. Vet. Zootec., v.57, p.261-265, 2005. 
HYÁNKOVÁ, L.; DEDKOVÁ, L.; KNIZETVÁ, $\mathrm{H}$. et al. Responses in growth, food intake and food conversion efficiency to different dietary protein concentrations in meat-type lines of japonese quail. Br. Poult. Sci., v.38, p.564-570, 1997.

LEE，T.K.; SHIM，K.F.; TAN， E.L. Protein requirement of growth Japanese quail in the tropics. Sing. J. Prim. Indian, v.5, p.70, 1977.

LEPORE, P.D.; MARKS, H.L. Growth rate inhentance in japanese quail. 5. Protein and energy requirements of lines selected under different nutritional environment. Poult. Sci., v.50, p.1335-1341, 1971.

MARKS, H.L. The influence of dietary protein levels on body weight of japanese quail lines selected under high and low protein diets. Poult. Sci., v.72, p.1012-1017, 1993.

MURAKAMI, A.E.; MORAES, V.M.B.; ARIKI, J. et al. Níveis de proteína e energia em rações para codornas japonesas (Coturnix coturnix japonica) em crescimento. Rev. Bras. Zootec., v.22, p.534-540, 1993.

NUTRIENT requirements of poultry. 9.ed. Washington: National Academy of Sciences, 1994. p.44-45.

OLIVEIRA, N.T.E.; SILVA, M.A.; SOARES, R.T.N. et al. Exigências de energia e proteína para codornas japonesas machos criadas para a produção de carne. In: REUNIÃO ANUAL DA SOCIEDADE BRASILEIRA DE ZOOTECNIA, 37., 2000, Viçosa. Anais... Viçosa: SBZ, 2000. p.89-91.

OLIVEIRA, N.T.E.; FONSECA, J.B.; SOARES, R.T.N. et al. Determinação da energia metabolizável de diferentes alimentos testados em codornas japonesas fêmeas. Arq. Bras. Med. Vet. Zootec., v.59, p.210-217, 2007.

OLIVEIRA, N.T.E.; SILVA, M.A.; SOARES, R. T. N. et al. Exigências de energia e proteína para codornas japonesas machos criadas para a produção de carne. Rev. Bras. Zootec., v.31, p. 675-686, 2002a.

OLIVEIRA, N.T.E.; SILVA, M.A.; SOARES, R.T.N. et al. Exigências de proteína bruta e energia metabolizável para codornas japonesas machos criadas para a produção de carne. Arq. Bras. Med. Vet. Zootec., v.54, p.196-203, 2002 b.

RAJINI, R.A.; NARAHARI, D. Dietary energy and protein requirements of growing japanese quails in the tropics. Indian J. Anim. Sci., v.68, p.1082-1086, 1998.

ROSTAGNO, H.S.; ALBINO, L.F.T.; DONZELE, J L. et al. Composição de Alimentos e exigências nutricionais de aves e suínos, (Tabelas brasileiras para aves e suínos). Viçosa, MG: UFV, 2000. 141p.

SUMMERS, J.D.; LEESON, S.; SPRATT, D. Yield and composition of edible meat form male broilers as influenced by dietary protein level and amino acid supplementation. Can. J. Anim. Sci., v.68, p.241-248, 1988.

SISTEMA de análises estatísticas e genéticas SAEG, Versão 9.0. Viçosa, MG: UFV, 2004.

VOHRA, P.; ROUDYBUSH, T. The effect of various levels of dietary protein on growth and egg production of Coturnix coturnix japonica. Poult. Sci., v.50, p.1081-1084, 1971. 